\title{
The leaf anatomy of a broad-leaved evergreen allows an increase in leaf nitrogen content in winter
}

\author{
Onno Mullera,b,e,*, Riichi Oguchic ${ }^{c}$, Tadaki Hirose ${ }^{d}$, Marinus J.A. Werger ${ }^{e}$ and Kouki Hikosaka ${ }^{a}$ \\ ${ }^{a}$ Graduate school of Life Sciences, Tohoku University, Aoba Sendai 980-8578, Japan \\ bTomakomai Research Station, Forest Research Station, Field Science Center for Northern Biosphere, Hokkaido University, Takaoka, Tomakomai, \\ Hokkaido, 053-0035, Japan \\ 'Graduate School of Sciences, The University of Tokyo, 7-3-1 Hongo, Bunkyo-ku 113-0033, Japan \\ ${ }^{\mathrm{d}}$ Tokyo University of Agriculture, Sakuragaoka 1-1-1, Setagaya, Tokyo 156-8502, Japan, \\ e Department of Plant Ecology and Biodiversity, Institute of Environmental Biology, Utrecht University, Sorbonnelaan 16, PO BOX 80084,3508 TB \\ Utrecht, The Netherlands
}

\section{Correspondence \\ ${ }^{*}$ Corresponding author, \\ e-mail: onnomuller@hotmail.com}

Received 19 November 2008; revised 6 February 2009

doi: 10.1111/j.1399-3054.2009.01224.x
In temperate regions, evergreen species are exposed to large seasonal changes in air temperature and irradiance. They change photosynthetic characteristics of leaves responding to such environmental changes. Recent studies have suggested that photosynthetic acclimation is strongly constrained by leaf anatomy such as leaf thickness, mesophyll and chloroplast surface facing the intercellular space, and the chloroplast volume. We studied how these parameters of leaf anatomy are related with photosynthetic seasonal acclimation. We evaluated differential effects of winter and summer irradiance on leaf anatomy and photosynthesis. Using a broadleaved evergreen Aucuba japonica, we performed a transfer experiment in which irradiance regimes were changed at the beginning of autumn and of spring. We found that a vacant space on mesophyll surface in summer enabled chloroplast volume to increase in winter. The leaf nitrogen and Rubisco content were higher in winter than in summer. They were correlated significantly with chloroplast volume and with chloroplast surface area facing the intercellular space. Thus, summer leaves were thicker than needed to accommodate mesophyll surface chloroplasts at this time of year but this allowed for increases in mesophyll surface chloroplasts in the winter. It appears that summer leaf anatomical characteristics help facilitate photosynthetic acclimation to winter conditions. Photosynthetic capacity and photosynthetic nitrogen use efficiency were lower in winter than in summer but it appears that these reductions were partially compensated by higher Rubisco contents and mesophyll surface chloroplast area in winter foliage.

\footnotetext{
Abbreviations $-C_{i}$, intercellular $\mathrm{CO}_{2}$ concentration $\left(\mu \mathrm{mol} \mathrm{mol}{ }^{-1}\right)$; $L M A$, leaf mass per area $\left(\mathrm{g} \mathrm{m}^{-2}\right)$; $\mathrm{N}_{\text {area, }}$ leaf nitrogen content per area $\left(\mathrm{mmol} \mathrm{m}^{-2}\right) ; \mathrm{N}_{\text {area }} \mathrm{N}_{\text {chl }}$, nitrogen concentration in the chloroplasts $\left(\mathrm{mmol} \mathrm{m}^{-3}\right) ; \mathrm{P}_{\max }$, photosynthetic capacity at saturated light and ambient $\mathrm{CO}_{2}\left(\mu \mathrm{mol} \mathrm{m} \mathrm{m}^{-2} \mathrm{~s}^{-1}\right)$; PNUE, photosynthetic nitrogen use efficiency $\left(\mathrm{mmol} \mathrm{mol}^{-1} \mathrm{~s}^{-1}\right)$; PPFD, photosynthetic photon flux density; Rubisco content, Ribulose-1,5-bisphosphate carboxylase/oxygenase content per leaf area $\left(\mathrm{g} \mathrm{m}^{-2}\right) ; \mathrm{S}_{\mathrm{c}}$, chloroplast surface area facing the intercellular space per unit leaf area $\left(\mathrm{m}^{2} \mathrm{~m}^{-2}\right) ; \mathrm{S}_{\mathrm{c}} / \mathrm{S}_{\mathrm{mes}}$, fraction of mesophyll surface area covered by chloroplasts; $S_{\text {mes}}$, mesophyll surface area facing the intercellular space per unit leaf area $\left(\mathrm{m}^{2} \mathrm{~m}^{-2}\right)$; $V_{c h l}$, chloroplast volume per unit leaf area $\left(\mathrm{m}^{3} \mathrm{~m}^{-2}\right) ; \mathrm{V}_{\mathrm{chl}} / \mathrm{S}_{\mathrm{c}}$, chloroplast thickness $(\mu \mathrm{m})$.
} 


\section{Introduction}

Evergreens inhabiting the understory in a temperate deciduous forest are exposed to large changes in temperature and light over the year. Air temperature is around the freezing point in winter and about $25^{\circ} \mathrm{C}$ in summer (Röhrig 1991). The irradiance in the understory changes dramatically with shedding and flushing of canopy leaves. Daily integrated photosynthetic photon flux density (PPFD) under an open canopy is 3- to 10-fold higher in winter than in summer despite the shorter day length (Skillman et al. 1996, Muller et al. 2005).

Leaves acclimate to changes in temperature and irradiance (e.g. Berry and Björkman 1981, Björkman 1981, Huner et al. 1998). In evergreens, several leaf traits change seasonally: they have more nitrogen and Rubisco, a higher $\mathrm{Chl}$ a/b ratio, a higher Rubisco/Chl ratio, and a lower $\mathrm{Chl} /$ nitrogen ratio in winter (Skillman et al. 1996). These parameters of photosynthesis are correlated to ambient temperature and irradiance (Muller et al. 2005), and may represent adaptive responses to the seasonal changes in environmental conditions.

Leaf anatomy has been shown to play an important role in photosynthetic acclimation in herbaceous and deciduous tree species. Leaves are thicker with a higher leaf nitrogen content and a higher $\mathrm{P}_{\max }$ when grown at high irradiance than at low irradiance (Terashima et al. 2001). Thicker leaves allow for a larger chloroplast surface area facing the intercellular space $\left(\mathrm{S}_{\mathrm{c}}\right)$, which is essential for efficient $\mathrm{CO}_{2}$ diffusion to the carboxylation site in the chloroplasts (von Caemmerer and Evans 1991, Evans et al. 1994, Terashima et al. 2001). However, mature leaves in most species do not have flexibility in leaf anatomy when environmental conditions change (Sims and Pearcy 1992). Recently Oguchi et al. (2003, $2005,2006)$ showed that shade leaves in an annual herb and several deciduous tree species had vacant space along the mesophyll cell surface, which allowed for an increase in $S_{c}$ and $P_{\max }$ when irradiance increased. On the other hand, shade leaves of Fagus crenata had less vacant space and changed neither leaf nitrogen content nor $\mathrm{P}_{\max }$ when irradiance increased (Oguchi et al. 2005). These results suggest that, to increase $P_{\max }$, leaves need to be thicker than the minimum to arrange all chloroplasts to fill the mesophyll surface (Oguchi et al. 2005). Although thick shade leaves are costly in terms of biomass investment, an increase in carbon gain with photosynthetic acclimation is greater than the invested biomass to allow acclimation if gaps are formed (Oguchi et al. 2008).

Although several studies showed that mature leaves of evergreen species change photosynthetic components in response to seasonal environmental changes (Skillman et al. 1996, Miyazawa and Kikuzawa 2005), there seems no study on the role of leaf anatomy, particularly of the vacant space in those changes. Because evergreen species in the understory of a deciduous forest are exposed to a large increase in irradiance and a decrease in temperature from summer to winter, we hypothesize that they have a large vacant space in summer to allow an increase in chloroplast volume toward winter. Alternatively, the leaf anatomy may limit an increase in $\mathrm{S}_{\mathrm{C}}$ and an increase in chloroplast volume would not increase the light-saturated photosynthetic rate at ambient $\mathrm{CO}_{2}\left(\mathrm{P}_{\max }\right)$. This might have been the case for the studies that showed a decrease in $\mathrm{P}_{\max }$ in spite of an increase in leaf nitrogen content in winter (Muller et al. 2005, Miyazawa and Kikuzawa 2005). If the increase in leaf nitrogen during winter was solely for a nonfunctional storage (Warren and Adams 2004), the leaf anatomy would maximize photosynthesis in summer and not in winter, and there would be no abundant vacant space along the mesophyll cell surface walls.

The aim of the study was to elucidate how leaf anatomy relates to the photosynthetic acclimation to the seasonal environment. More specifically, our question was whether leaf anatomy was to maximize photosynthesis in summer or in winter. To answer this question, we performed a transfer experiment in which irradiance of the plants was changed at the beginning of autumn and of spring. If leaf anatomy was to maximize photosynthesis in winter, plants that were exposed to high irradiance in winter would have greater leaf thickness irrespective of irradiance in summer. If it was to minimize biomass investment, leaf thickness would be determined by irradiance in summer. We raised Aucuba japonica, an evergreen shrub in temperate forests in Japan, for 2 years at different irradiance regimes under the natural seasonal changes in temperature. Seasonal changes in photosynthetic and anatomical traits were studied on new leaves in the second year of the experiment.

\section{Materials and methods}

Aucuba japonica Thunb. is a common understory shrub in Japan. It is evergreen and dioecious with relatively large and long-lived leaves. Under natural conditions in central Japan the mean life span of leaves was 2.6 years (Yamamura 1992). After bud break in April it flowers, expands new leaves and shed the oldest leaves within about one month.

In August 2001, we collected saplings in the forest dominated by Quercus serrata adjacent to the experimental garden $\left(38^{\circ} 15^{\prime} \mathrm{N} 140^{\circ} 50^{\prime} \mathrm{E}\right)$ of Tohoku University. The saplings were about $20 \mathrm{~cm}$ high and 
3-4 years old. They were not branched, and had 2-4 current-year leaves and 2-4 previous-year leaves. A. japonica had relatively thick roots that were easily excavated from the humus layer of the forest soil without visible damage to the roots. The saplings were potted individually in $4 \mathrm{I}$ pots in a 16:3 mixture of kiryusuna (Japanese volcanic sand) and pelapon (cocos fiber). Each pot received $20 \mathrm{ml}$ of a commercial nutrient solution (1.8 mM [N], Hyponex NPK = 6:10:5) weekly. Additional water was provided when needed. In winter, nutrients were given every two weeks. The plants were grown under one or three layers of neutral shading cloth, high and low irradiance, respectively, in a vinyl house with open sides. Irradiance (PPFD) was measured with a quantum sensor (LI190-SA, Li-Cor Inc, Lincoln, $\mathrm{NE}$ ) connected to a data logger (LI1000, Li-Cor) at $1 \mathrm{~h}$ intervals. Temperature in the vinyl house was measured with Onset temperature loggers (StowAway Tidbit Temperature logger, Onset, MA).

Plants were allotted randomly to four sets with different irradiance regimes to test the effect of irradiance in relation to temperature over the years. One set of plants was grown at high irradiance $\left(I_{\text {high }}\right)$ and the second at low irradiance ( $\left.\mathrm{I}_{\text {low }}\right)$ throughout for 2 years. The third set of plants was grown at high irradiance in winter and low irradiance in summer $\left(\mathrm{I}_{\mathrm{dec}}\right)$ simulating the deciduous understory conditions. The fourth set was inversely related to the previous one with low irradiance in winter and high irradiance in summer $\left(\mathrm{I}_{\text {inv }}\right) . I_{\text {dec }}$ and $I_{\text {inv }}$ sets of plants were transferred between high and low irradiance treatments on November 20, 2002, May 3, 2003, November 10, 2003 and April 25, 2004 (Fig.1), approximately at the time when the surrounding deciduous forests shed old leaves (November) or flushed new leaves (April/May). Photosynthetic measurements were taken in the second year from summer 2003 to spring 2004.

Three healthy plants were selected from each of the four irradiance regimes $\left(I_{\text {high }}, I_{\text {low }}, I_{\text {dec }}, I_{\text {inv }}\right)$ for photosynthesis measurement and biochemical analyses every season. Measurements were taken in the laboratory within about 2 weeks: summer, August 15-30, 2003; autumn, November 26-December 5 2003; winter, January 30-February 12 2004; spring May 20-May 30 2004. Thus measurements were taken more than 2 weeks after transfer in $I_{\text {dec }}$ and $I_{\text {inv. }}$. One nonshaded leaf per plant was selected for photosynthesis measurements on the attached leaf using a portable gas exchange system (Li-6400-40, Li-Cor). The lightsaturated rate of photosynthesis $\left(\mathrm{P}_{\max }\right)$ was determined at a $\mathrm{CO}_{2}$ concentration of $370 \mu \mathrm{mol} \mathrm{mol}{ }^{-1}$, PPFD of $1000 \mu \mathrm{mol} \mathrm{m} \mathrm{m}^{-2} \mathrm{~s}^{-1}$, leaf temperature of $15^{\circ} \mathrm{C}$ and $80 \%$ relative humidity. After photosynthesis measurements in

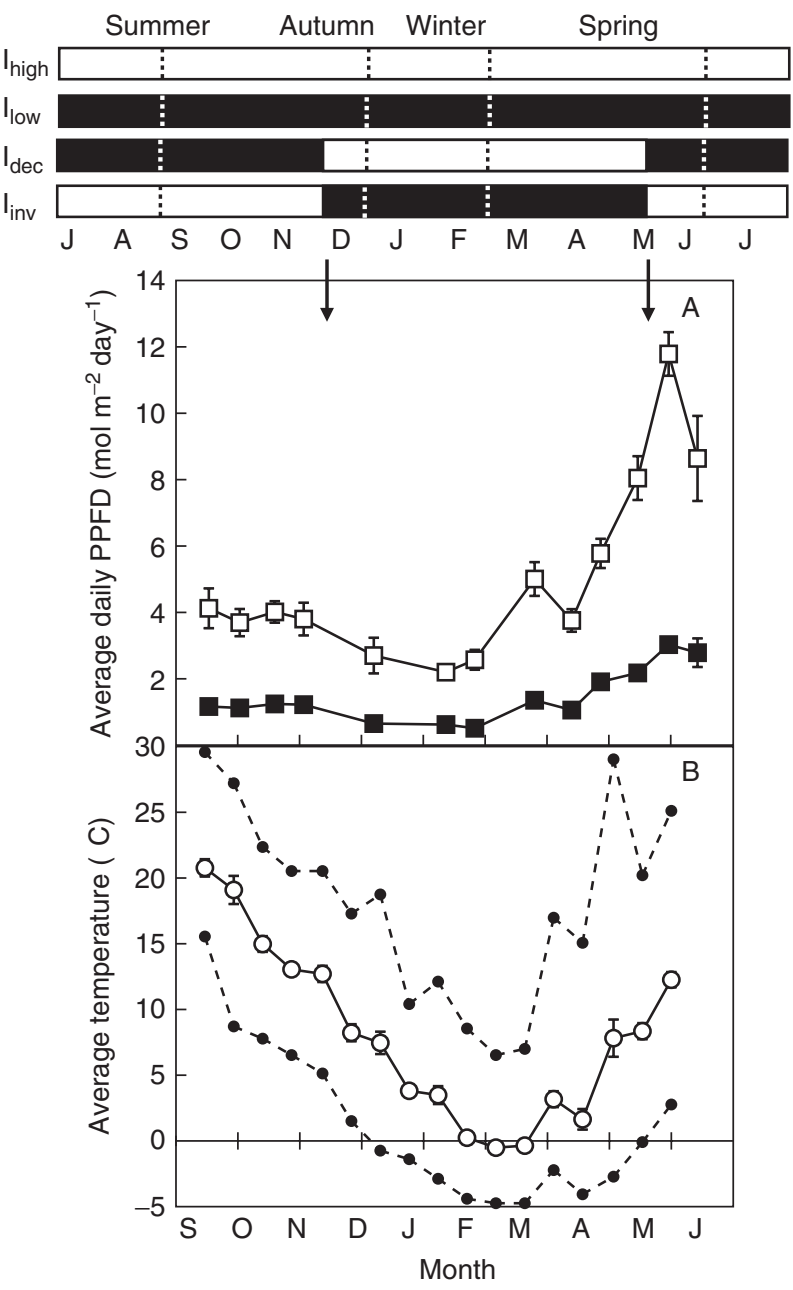

Fig. 1. Changes in PPFD (A) and temperature (B) over the year with a scheme of the irradiance regimes on top. The open and closed bars indicate high and low irradiance regimes, respectively. The dotted lines indicate when photosynthesis measurements were performed and the arrows when plants were transferred. The 10-day average PPFD of the high (open symbols) and low (closed symbols) irradiance regime $(A)$ and the 10-day mean average temperature and absolute minimum and maximum values from August 2003 to May 2004 (B). Values are means \pm SE.

a controlled-temperature room, the plants were returned to their respective irradiance regime outside. Within 1-2 days, the leaves used for photosynthesis were harvested in the morning and subjected to biochemical analysis and leaf anatomy. For these analyses at least five leaf discs of $10 \mathrm{~mm}$ in diameter were punched out per leaf in the laboratory.

Three leaf discs were dried at $80^{\circ} \mathrm{C}$ for more than 3 days. After dry mass determination, nitrogen $(\mathrm{N})$ content was determined with a nitrogen carbon analyzer (NC-80, Shimadzu, Kyoto, Japan). At least two leaf discs were stored at $-80^{\circ} \mathrm{C}$ for the determination 
of Rubisco as described in Muller et al. (2005). Of the remaining leaf, sections of about $1 \mathrm{~mm} \times 2 \mathrm{~mm}$ were cut out and directly prepared for light microscopy as described by Oguchi et al. (2003). The fixated leaves were embedded in Spurr's resin and $0.8 \mu \mathrm{m}$ thick cross sections were cut. One or two cross sections per leaf were analyzed using the image processing software imagej v1.36b (NIH, MD). The surface area of mesophyll cells facing the intercellular space $\left(S_{\text {mes }}\right)$, the area of chloroplast surfaces facing the intercellular space $\left(S_{c}\right)$, and the total chloroplast volume per unit leaf area $\left(\mathrm{V}_{\mathrm{chl}}\right)$ were calculated. To convert length in cross section to surface area, a curvature factor (F) was determined assuming that the shape of the palisade cells was a cylinder with flat ends and that the sponge cell was a spheroid (Thain 1983). F was 1.26-1.35 in palisade and $1.12-1.23$ in spongy cells.

The value of $\mathrm{P}_{\max }$ was analyzed as the product of leaf nitrogen content per leaf area $\left(\mathrm{N}_{\text {area }}\right)$ and the photosynthetic nitrogen use efficiency (PNUE):

$$
P_{\max }=N_{\text {area }} \cdot \text { PNUE }
$$

Considering that most leaf $\mathrm{N}$ is in chloroplasts (Evans 1989) and that arrangement of chloroplasts along mesophyll surface is affected by various morphological parameters, $\mathrm{N}_{\text {area }}$ was analyzed as follows (Oguchi et al. 2005):

$$
\mathrm{N}_{\text {area }}=\mathrm{N}_{\text {area }} / \mathrm{V}_{\mathrm{chl}} \cdot \mathrm{V}_{\mathrm{chl}} / \mathrm{S}_{\mathrm{c}} \cdot \mathrm{S}_{\mathrm{c}} / \mathrm{S}_{\text {mes }} \cdot \mathrm{S}_{\text {mes }}
$$

$\mathrm{N}_{\text {area }} / \mathrm{N}_{\text {chl }}$ indicates the $\mathrm{N}$ concentration per unit chloroplast volume, if a fixed fraction of leaf $\mathrm{N}$ is in chloroplasts (Evans 1989), $\mathrm{V}_{\mathrm{chl}} / \mathrm{S}_{\mathrm{c}}$ indicates chloroplast thickness, $S_{C} / S_{\text {mes }}$ is the fraction of chloroplast area facing the intercellular space.

PNUE was analyzed as the product of the following factors:

$$
\text { PNUE }=\mathrm{P}_{\max } / \text { Rubisco } \cdot \text { Rubisco } / \mathrm{N}_{\text {area }}
$$

where Rubisco is the Rubisco content per leaf area. $\mathrm{P}_{\max } /$ Rubisco may decrease when the $\mathrm{CO}_{2}$ concentration in the chloroplast decreases (Hikosaka et al. 1998), when the activation state of Rubisco and of other photosynthetic proteins decreases (Mott and Woodrow 2000), or when photoinhibition occurs (Adams et al. 2004). Rubisco/ $\mathrm{N}_{\text {area }}$ indicates the nitrogen partitioning between photosynthetic and non-photosynthetic components within leaves (Hikosaka 2004).

The effects of irradiance and temperature on leaf traits over the year were tested by ANOVA. The effects of summer and winter irradiance were tested by grouping the sets of plants with the same irradiance in summer and winter, i.e. $I_{\text {high }}$ and $I_{\text {inv }}$ (high irradiance in summer) vs $I_{\text {low }}$ and $I_{\text {dec }}$ (low irradiance in summer) to test the 'summer-irradiance' effect and $I_{\text {high }}$ and $I_{\text {dec }}$ (high irradiance in winter) vs $I_{\text {low }}$ and $I_{\text {inv }}$ (low irradiance in winter) to test the 'winter-irradiance' effect by ANOVA. Statistical analyses were done using SYSTAT (Systat Software Inc., San Jose).

\section{Results}

\section{Growth conditions}

The daily average PPFD was on average $5.1 \mathrm{~mol} \mathrm{~m}^{-2}$ day $^{-1}$ (ranging from 2.2 to 11.8 over the year) in high irradiance and $1.4 \mathrm{~mol} \mathrm{~m}^{-2}$ day $^{-1}$ (ranging from 0.5 to 3.0 over the year, Fig. 1A) in low irradiance. In both irradiance levels, the daily average PPFD decreased gradually from summer to winter, and increased sharply toward spring as a result of the increase in the solar elevation and the predominance of a clear sky. The seasonal change in temperature ranged from a daily average temperature of $21.2^{\circ} \mathrm{C}$ in August to $-0.5^{\circ} \mathrm{C}$ in January (Fig. 1B). The monthly maximum and minimum temperatures were on average $10.1^{\circ} \mathrm{C}$ higher and $6.8^{\circ} \mathrm{C}$ lower, respectively, than the daily average temperature. The two irradiance regimes had no discernible effect on daily average, minimum or maximum temperatures during the year (data not shown).

\section{Seasonal change in physiological and morphological traits}

There was a significant seasonal change in $P_{\max }$, which tended to decrease from summer to winter (Fig. 2A, Table 1). Although growth irradiance did not significantly affect $P_{\max }$, there was a significant interaction between season and growth irradiance in the effect on $P_{\max }$ (Table 1). In summer, $P_{\max }$ tended to be higher in high irradiance $\left(I_{\text {high }}\right.$ and $\left.I_{\text {inv }}\right)$ than in low irradiance regimes ( $I_{\text {low }}$ and $I_{\text {dec }}$ ), while in winter, an opposite pattern was observed in which $\mathrm{P}_{\max }$ was higher in low irradiance regimes $\left(I_{\text {low }}\right.$ and $\left.I_{\text {inv }}\right)$. $N_{\text {area }}$ also showed a significant seasonal change (Table 1). $\mathrm{N}_{\text {area }}$ increased from summer to autumn in $I_{\text {low }}$ and $I_{\text {dec, }}$, or from summer to winter in $I_{\text {high }}$ and $I_{\text {inv }}$ (Fig. 2B). In spring $N_{\text {area }}$ decreased to similar values of the previous summer. $\mathrm{N}_{\text {area }}$ tended to be higher in leaves exposed to high irradiance in winter ( $I_{\text {high }}$ and $I_{\text {dec }}$ ) than those in low irradiance in winter ( $I_{\text {low }}$ and $I_{\text {inv }}$ ) through the year (Fig. 2B). PNUE decreased from summer to winter in parallel to changes in $P_{\max }$. In summer and autumn, PNUE was higher in plants grown at high summerirradiance regimes $\left(I_{\text {high }}\right.$ and $\left.I_{\text {inv }}\right)$, whereas in winter PNUE was highest in the plants growing at low irradiance (I low and $I_{\text {inv }}$ ). 


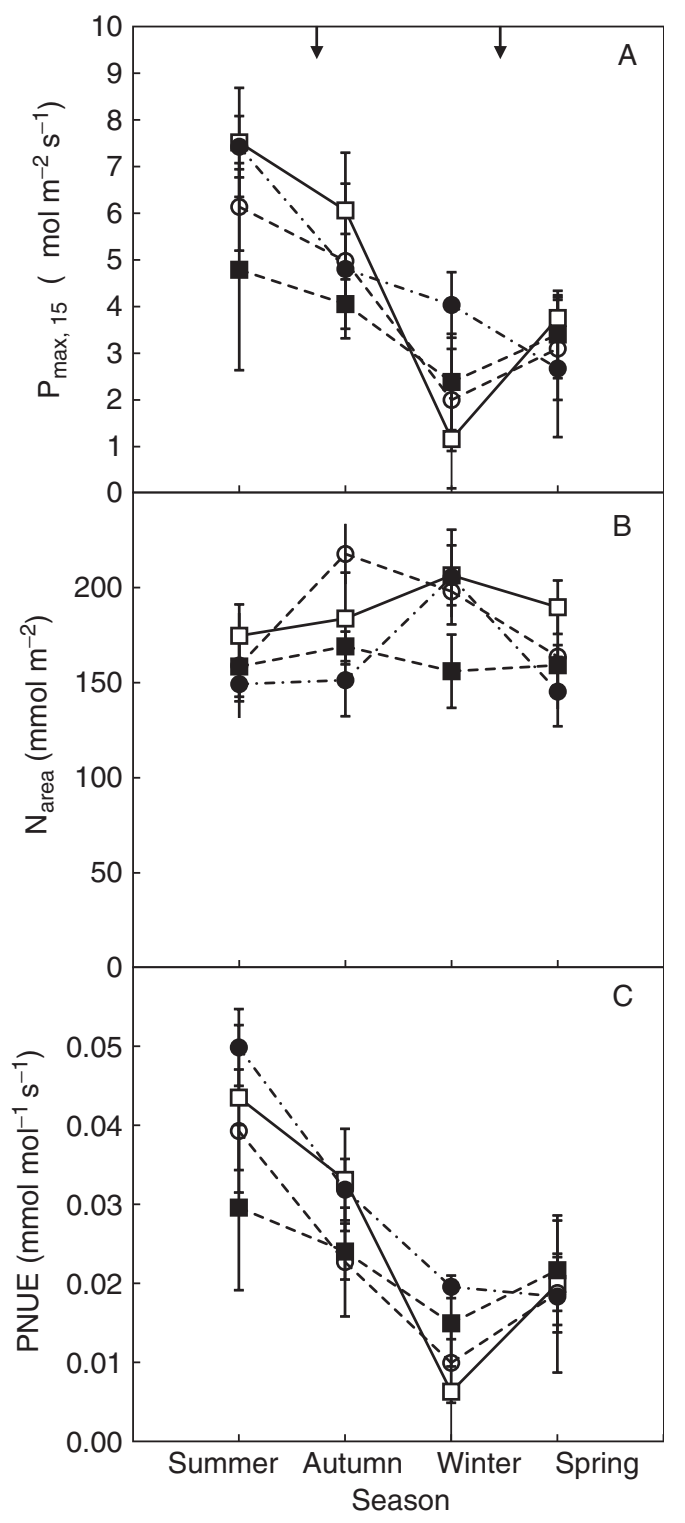

Fig. 2. Seasonal changes in photosynthetic capacity measured at $15^{\circ} \mathrm{C}$ $\left(P_{\max }\right), N_{\text {area }}$ and photosynthetic nitrogen use efficiency (PNUE). The average is shown for Aucuba japonica grown all the year at high ( $I_{\text {high }}$, open squares, solid line) and low (I low, closed squares, dotted line) irradiance and plants transferred in autumn from low to high $\left(I_{\mathrm{dec}}\right.$, open circles, broken line) or from low to high ( $l_{\text {inv, }}$ closed circles, broken dotted line) irradiance and vice versa in spring. Values are mean \pm SD ( $n$ $=3$ ). Arrows indicate the time when plants were transferred.

The Rubisco content changed significantly in a similar pattern to $\mathrm{N}_{\text {area }}$ and was highest in autumn ( $\mathrm{I}_{\text {high }}$ and $I_{\text {dec }}$ ) or winter ( $I_{\text {low }}$ and $I_{\text {inv }}$ ) (Table 2). $C_{i}$ showed significant seasonal changes (Table 1 ). $C_{i}$ first decreased from summer to autumn, and then increased or remained similar $\left(I_{\text {inv }}\right)$ in winter and thereafter decreased to its lowest values of the year in spring (Table 2). Leaf mass per area (LMA) showed a significant seasonal change and was also significantly different between irradiance regimes (Table 1). LMA increased from summer to winter and was higher at high irradiance regimes from summer to winter (Table 2).

Cross sections of $I_{\text {high }}$ and $I_{\text {low }}$ leaves in summer and winter are illustrated by light microscopic photographs (Fig. 3). Although $I_{\text {high }}$ leaves seem to have one more palisade layer than $I_{\text {low, }}$, there was no significant effect of season and growth irradiance on leaf thickness (Fig. 4) and $S_{\text {mes }}$ (mesophyll surface area, Tables 1 and 3). On the other hand, there were significant effects of season and growth irradiance on chloroplast morphologies. $V_{\text {chl }}$ (chloroplast volume per leaf area) changed seasonally, and $\mathrm{S}_{\mathrm{c}}$ (chloroplast surface area) was affected by growth irradiance (Table 1 ). Both $\mathrm{V}_{\mathrm{chl}}$ and $\mathrm{S}_{\mathrm{c}}$ were higher in autumn/winter and at high irradiance (Fig. 4B, C). Reflecting the changes in $\mathrm{S}_{\mathrm{C}}, \mathrm{S}_{\mathrm{C}} / \mathrm{S}_{\text {mes }}$ tended to be higher in autumn/winter (Table 3 ). $\mathrm{V}_{\mathrm{ch}} / \mathrm{S}_{\mathrm{c}}$ (chloroplast thickness) also showed a seasonal change and tended to increase in winter (Tables 1,3 ). However, $N_{\text {area }} / N_{\text {chl }}$, which indicates the protein concentration in chloroplasts, was not affected by season and growth irradiance (Tables 1, 3).

\section{Relationships among parameters}

The chloroplast related traits were correlated significantly with leaf nitrogen content except $S_{\text {mes }}$ (Fig. 5). $V_{c h l}, V_{c h l} / S_{c}$ and $S_{c}$ all increased with $N_{\text {area }}$ with no differences between seasons (ANCOVA among slopes $P=0.50,0.33$ and 0.92 , among intercepts $P=0.47,0.06$ and 0.23 for $\mathrm{V}_{\mathrm{chl}}, \mathrm{V}_{\mathrm{chl}} / \mathrm{S}_{\mathrm{c}}$ and $\mathrm{S}_{\mathrm{c}}$, respectively). There was a positive linear relation between the Rubisco content and $\mathrm{N}_{\text {area }}$ (Fig. 6B) that differed between seasons (ANCOVA: among slopes $P=0.48$ and intercepts $P=0.03$ ). The Rubisco content at a given $\mathrm{N}_{\text {area }}$ increased from summer to spring. $\mathrm{P}_{\max }$ was positively correlated with the Rubisco content in autumn and winter but was not in the other seasons (Fig. 6A). The $\mathrm{P}_{\max } /$ Rubisco ratio was correlated negatively with $\mathrm{V}_{\text {chl }} / \mathrm{S}_{\mathrm{c}}$ (Fig. 7A) and positively with $\mathrm{C}_{\mathrm{i}}$ (Fig. 7B) across all seasons.

\section{Effects of summer and winter irradiance}

Summer irradiance had significant effects on $\mathrm{P}_{\max }$ and PNUE (Table 1): Both $P_{\max }$ and PNUE in summer were higher in leaves that were in high irradiance in summer (Fig. 2). However, other traits were less affected by summer irradiance. On the other hand, winter irradiance affected more photosynthetic traits (Table 1). $\mathrm{N}_{\text {area }}, \mathrm{C}_{\mathrm{i}}$, $V_{c h l}$ and $S_{c}$ were higher in leaves that were exposed to 
Table 1. Effects of season and irradiance on leaf anatomy and physiology traits. The effect on leaf physiological and anatomical traits of season and growth irradiance (irradiance plants are exposed to, i.e. $I_{\text {high }}, I_{\text {low }}, I_{\text {dec }}, I_{\text {inv }}$, see text and Fig. 1), summer irradiance (irradiance plants are exposed to in summer, i.e. $I_{\text {high }}$ and $I_{\text {inv }} v s I_{\text {low }}$ and $I_{\text {dec }}$ ) or winter irradiance (irradiance plants are exposed to in winter, i.e. $I_{\text {high }}$ and $I_{\text {dec }} v s I_{\text {low }}$ and $I_{\text {inv }}$ ), tested by ANOVA. $P$ values are shown, in bold when $P<0.05$.

\begin{tabular}{|c|c|c|c|c|c|c|c|c|c|}
\hline Variable & Season & $\begin{array}{l}\text { Growth } \\
\text { irradiance }\end{array}$ & Interaction & Season & $\begin{array}{l}\text { Summer } \\
\text { irradiance }\end{array}$ & Interaction & Season & $\begin{array}{l}\text { Winter } \\
\text { irradiance }\end{array}$ & Interaction \\
\hline$P_{\max }\left(\mu \mathrm{mol} \mathrm{m} \mathrm{m}^{-2} \mathrm{~s}^{-1}\right)$ & 0.000 & 0.100 & 0.001 & 0.000 & 0.005 & 0.119 & 0.000 & 0.902 & 0.139 \\
\hline $\mathrm{N}_{\text {area }}\left(\mathrm{mmol} \mathrm{m} \mathrm{m}^{-2}\right)$ & 0.006 & 0.215 & 0.763 & 0.004 & 0.112 & 0.442 & 0.003 & 0.006 & 0.878 \\
\hline PNUE $\left(\mathrm{mmol} \mathrm{mol}^{-1} \mathrm{~s}^{-1}\right)$ & 0.000 & 0.095 & 0.002 & 0.000 & 0.008 & 0.078 & 0.000 & 0.556 & 0.449 \\
\hline Leaf thickness $(\mu \mathrm{m})$ & 0.290 & 0.423 & 0.931 & 0.280 & 0.991 & 0.276 & 0.297 & 0.617 & 0.971 \\
\hline$V_{c h l}\left(m^{3} m^{-2}\right)$ & 0.007 & 0.057 & 0.313 & 0.018 & 0.761 & 0.299 & 0.003 & 0.001 & 0.584 \\
\hline $\mathrm{S}_{\mathrm{c}}\left(\mathrm{m}^{2} \mathrm{~m}^{-2}\right)$ & 0.050 & 0.021 & 0.724 & 0.105 & 0.293 & 0.796 & 0.046 & 0.007 & 0.645 \\
\hline$C_{i}\left(\mu \mathrm{mol} \mathrm{mol}{ }^{-1}\right)$ & 0.000 & 0.907 & 0.113 & 0.000 & 0.621 & 0.615 & 0.000 & 0.004 & 0.485 \\
\hline Rubisco $\left(\mathrm{g} \mathrm{m}^{-2}\right)$ & 0.000 & 0.532 & 0.665 & 0.000 & 0.170 & 0.949 & 0.000 & 0.064 & 0.302 \\
\hline LMA $\left(\mathrm{g} \mathrm{m}^{-2}\right)$ & 0.000 & 0.002 & 0.224 & 0.000 & 0.124 & 0.892 & 0.000 & 0.000 & 0.162 \\
\hline$N_{\text {area }} N_{\text {chl }}\left(\mathrm{mmol} \mathrm{m}^{-3}\right)$ & 0.585 & 0.340 & 0.459 & 0.660 & 0.575 & 0.035 & 0.593 & 0.160 & 0.970 \\
\hline $\mathrm{V}_{\mathrm{chl}} / \mathrm{S}_{\mathrm{c}}(\mu \mathrm{m})$ & 0.010 & 0.657 & 0.089 & 0.011 & 0.330 & 0.035 & 0.006 & 0.004 & 0.572 \\
\hline $\mathrm{S}_{\mathrm{C}} / \mathrm{S}_{\mathrm{mes}}$ & 0.001 & 0.260 & 0.655 & 0.001 & 0.391 & 0.447 & 0.001 & 0.231 & 0.874 \\
\hline$S_{\text {mes }}\left(m^{2} m^{-2}\right)$ & 0.404 & 0.165 & 0.204 & 0.452 & 0.779 & 0.940 & 0.393 & 0.049 & 0.286 \\
\hline
\end{tabular}

Table 2. Changes in leaf traits in four irradiance regimes. Seasonal changes per irradiance regime of $\mathrm{C}_{\mathrm{i}}$ (intercellular $\mathrm{CO}_{2}$ concentration), Rubisco (Rubisco per leaf area) and LMA (leaf mass per area). Values are the mean \pm standard deviation.

\begin{tabular}{|c|c|c|c|c|}
\hline & Summer & Autumn & Winter & Spring \\
\hline \multicolumn{5}{|c|}{$C_{i}\left(\mu \mathrm{mol} \mathrm{mol}^{-1}\right)$} \\
\hline$I_{\text {high }}$ & $217 \pm 10$ & $176 \pm 38$ & $251 \pm 59$ & $163 \pm 14$ \\
\hline$I_{\text {low }}$ & $199 \pm 10$ & $179 \pm 39$ & $195 \pm 25$ & $173 \pm 29$ \\
\hline$I_{\text {dec }}$ & $254 \pm 6$ & $174 \pm 35$ & $205 \pm 54$ & $154 \pm 42$ \\
\hline $\begin{array}{l}l_{\text {inv }} \\
\text { Rub }\end{array}$ & $214 \pm 2$ & $183 \pm 30$ & $183 \pm 27$ & $136 \pm 20$ \\
\hline$I_{\text {high }}$ & $2.8 \pm 0.5$ & $4.1 \pm 0.8$ & $2.8 \pm 0.1$ & $3.4 \pm 1.1$ \\
\hline$I_{\text {low }}$ & $2.0 \pm 0.5$ & $2.3 \pm 0.7$ & $2.9 \pm 0.6$ & $2.8 \pm 0.5$ \\
\hline$I_{\mathrm{dec}}$ & $2.0 \pm 0.4$ & $3.5 \pm 0.6$ & $3.4 \pm 0.3$ & $3.4 \pm 0.3$ \\
\hline $\begin{array}{l}\mathrm{I}_{\text {inv }} \\
\mathrm{LM} A\end{array}$ & $1.9 \pm 0.1$ & $2.4 \pm 1.2$ & $3.8 \pm 0.8$ & $2.8 \pm 0.4$ \\
\hline$I_{\text {high }}$ & $77 \pm 11$ & $76 \pm 7$ & $99 \pm 1$ & $100 \pm 17$ \\
\hline$I_{\text {low }}$ & $63 \pm 3$ & $66 \pm 2$ & $74 \pm 2$ & $79 \pm 15$ \\
\hline$I_{\text {dec }}$ & $65 \pm 11$ & $80 \pm 3$ & $100 \pm 5$ & $91 \pm 13$ \\
\hline$I_{\text {inv }}$ & $66 \pm 2$ & $72 \pm 3$ & $83 \pm 3$ & $77 \pm 2$ \\
\hline
\end{tabular}

high irradiance in winter (Figs. 2, 4, Tables 1, 2). LMA and $S_{\text {mes }}$ were also higher in leaves that were exposed to high irradiance in winter (Tables 2, 3). These results suggest that leaf morphology was more strongly determined by winter irradiance than summer irradiance.

\section{Discussion}

\section{Morphology and function}

We found that there was a large vacant space for chloroplast arrangement along mesophyll surface (i.e. $1-S_{C} / S_{\text {mes }}$ ) in summer (Table 3). This enabled $S_{c}$ to increase with increasing $N_{\text {area }}$ in winter (Figs 2, 4, 5)
Table 3. Factors explaining the seasonal change in $\mathrm{N}_{\text {area. }}$. The factors that explain the seasonal changes in $N_{\text {area }}\left(N_{\text {area }} N_{\text {chl }}, V_{c h l} / S_{c}, S_{c} / S_{\text {mes }}\right.$ and $\left.S_{\text {mes }}\right)$ in different light treatments $\left(I_{\text {high }}, I_{\text {low }}, I_{\text {dec }}, l_{\text {inv }}\right)$. Values are mean \pm standard deviation.

\begin{tabular}{|c|c|c|c|c|}
\hline & Summer & Autumn & Winter & Spring \\
\hline \multicolumn{5}{|c|}{$\mathrm{N}_{\text {area }} / \mathrm{V}_{\text {chl }}\left(\mathrm{mmol} \mathrm{m}^{-3}\right)$} \\
\hline $\mathrm{I}_{\text {high }}$ & $3.28 \pm 0.93$ & $2.45 \pm 0.53$ & $3.24 \pm 1.48$ & $2.73 \pm 0.88$ \\
\hline$I_{\text {low }}$ & $3.41 \pm 0.41$ & $3.31 \pm 0.20$ & $2.45 \pm 0.52$ & $4.05 \pm 0.66$ \\
\hline$I_{\text {dec }}$ & $2.79 \pm 0.48$ & $2.86 \pm 0.25$ & $2.32 \pm 0.33$ & $2.82 \pm 0.89$ \\
\hline $\mathrm{I}_{\text {inv }}$ & $3.11 \pm 0.17$ & $2.88 \pm 0.61$ & $3.40 \pm 0.37$ & $2.69 \pm 0.09$ \\
\hline \multicolumn{5}{|c|}{$\mathrm{V}_{\mathrm{chl}} / \mathrm{S}_{\mathrm{c}}(\mu \mathrm{m})$} \\
\hline $\mathrm{l}_{\text {high }}$ & $3.85 \pm 0.48$ & $4.25 \pm 0.28$ & $4.46 \pm 1.02$ & $5.00 \pm 0.96$ \\
\hline$I_{\text {low }}$ & $3.81 \pm 0.17$ & $3.61 \pm 0.25$ & $4.80 \pm 0.63$ & $3.36 \pm 1.05$ \\
\hline$I_{\mathrm{dec}}$ & $4.21 \pm 0.21$ & $4.40 \pm 0.40$ & $4.81 \pm 0.31$ & $4.20 \pm 0.50$ \\
\hline $\mathrm{I}_{\text {inv }}$ & $3.50 \pm 0.02$ & $3.88 \pm 0.15$ & $4.01 \pm 0.25$ & $4.16 \pm 0.19$ \\
\hline \multicolumn{5}{|c|}{$\mathrm{S}_{\mathrm{c}} / \mathrm{S}_{\mathrm{mes}}$} \\
\hline I high & $0.71 \pm 0.02$ & $0.77 \pm 0.02$ & $0.66 \pm 0.20$ & $0.69 \pm 0.16$ \\
\hline$I_{\text {low }}$ & $0.61 \pm 0.07$ & $0.72 \pm 0.04$ & $0.72 \pm 0.09$ & $0.66 \pm 0.04$ \\
\hline$I_{\text {dec }}$ & $0.59 \pm 0.02$ & $0.72 \pm 0.03$ & $0.81 \pm 0.02$ & $0.73 \pm 0.11$ \\
\hline$I_{\text {inv }}$ & $0.61 \pm 0.04$ & $0.66 \pm 0.04$ & $0.79 \pm 0.04$ & $0.68 \pm 0.03$ \\
\hline \multicolumn{5}{|c|}{$S_{\text {mes }}\left(m^{2} m^{-2}\right)$} \\
\hline $\mathrm{l}_{\text {high }}$ & $20.4 \pm 3.4$ & $23.2 \pm 1.0$ & $23.7 \pm 0.5$ & $21.3 \pm 0.3$ \\
\hline$I_{\text {low }}$ & $20.4 \pm 4.5$ & $19.9 \pm 1.0$ & $18.7 \pm 1.4$ & $18.7 \pm 3.6$ \\
\hline$I_{\mathrm{dec}}$ & $23.1 \pm 0.8$ & $24.1 \pm 2.3$ & $22.2 \pm 3.7$ & $20.5 \pm 1.3$ \\
\hline $\mathrm{I}_{\text {inv }}$ & $22.6 \pm 0.8$ & $20.8 \pm 2.2$ & $19.2 \pm 1.3$ & $19.7 \pm 2.1$ \\
\hline
\end{tabular}

in spite of constant $S_{\text {mes }}$ (Table 3). This change in $S_{c}$ from summer to winter was similar to that observed in an annual and several deciduous tree species when their shade leaves were transferred to high irradiance (Oguchi et al. 2003, 2005, 2006). Just as the leaf anatomy of shade-tolerant plants has been shown to allow for increases in $\mathrm{S}_{\mathrm{c}}$ following gap formation, results presented 


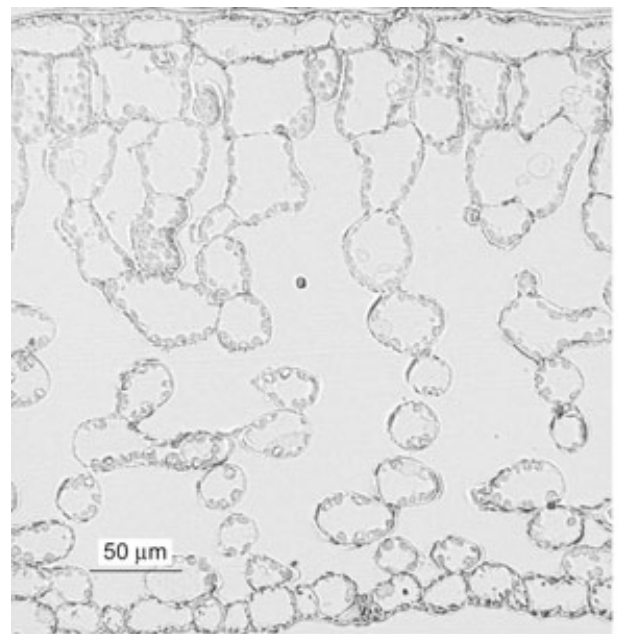

A

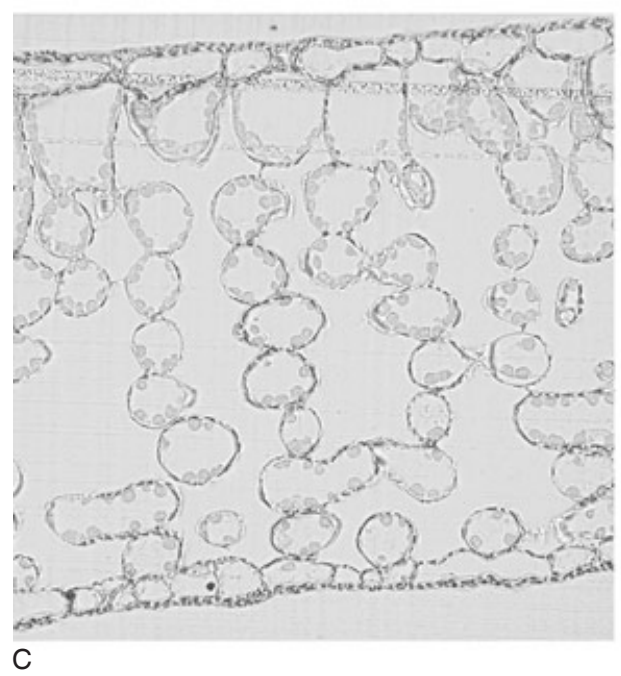

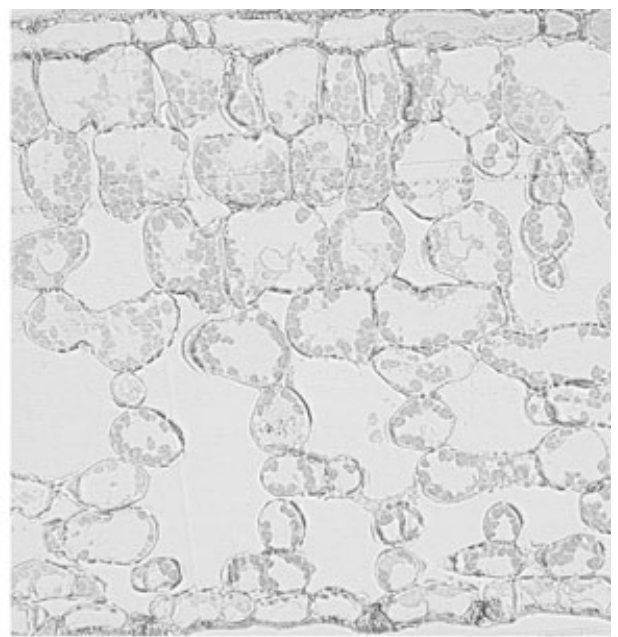

B

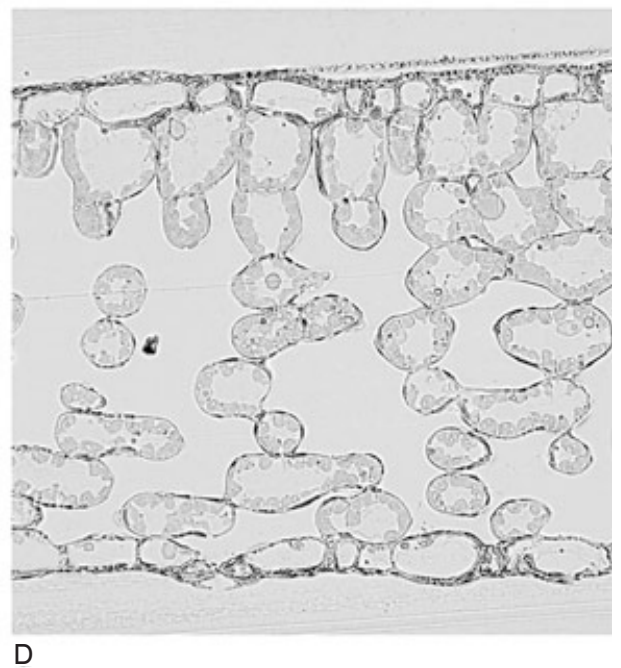

Fig. 3. Leaf cross sections of Aucuba japonica grown at high irradiance ( $\left.\mathrm{l}_{\text {high }}\right)$ in summer $(\mathrm{A})$ and in winter (B) or at low irradiance (l low) in summer (C) and in winter (D).

here indicate that leaves were thicker than needed in the summer which facilitated acclimation-related increases in $\mathrm{S}_{\mathrm{c}}$ in the winter.

Nevertheless, the increase in $\mathrm{S}_{\mathrm{C}}$ from summer to winter did not contribute to increasing photosynthetic rates. Rather, $\mathrm{P}_{\max }$ decreased substantially from summer to winter/spring when PNUE also decreased (Fig. 2). As the Rubisco content per unit nitrogen did not decrease (Fig. 6), the reduction in $P_{\max }$ and PNUE should be ascribed to a decrease in $P_{\max }$ per unit Rubisco (Fig. 6, see Eqn 3). The decrease in $P_{\max }$ per Rubisco from summer to autumn has also been observed in Tiarella cordifolia and Daphniphyllum humile growing in the understory (Rothstein and Zak 2001, Katahata et al. 2005). The change in $P_{\max } /$ Rubisco ratio is attributable to (1) changes in properties of Rubisco (i.e. decreased
Rubisco activation state), (2) inhibition of the photosynthetic apparatus, or (3) limited supply of $\mathrm{CO}_{2}$. The first possibility recalls the argument that evergreen leaves accumulate Rubisco as an inactive storage protein in winter (Warren and Adams 2004). However, it does not explain the increase in Rubisco in spring, when Rubisco, if stored, would be used for new leaf formation (Table 2).

The second and third possibilities for the decrease in $P_{\max }$ per Rubisco are related to stress in low temperature and high irradiance in winter. Recent studies have shown that the rate of Rubisco-limited photosynthesis decreases with increasing photoinhibition (Hikosaka et al. 2004, Hirotsu et al. 2005, Miyazawa et al. 2007). The plants grown at high irradiance in winter had a high $C_{i}$ but lower $P_{\max }$ and PNUE values than plants growing at low irradiance (Fig. 2), suggesting an 


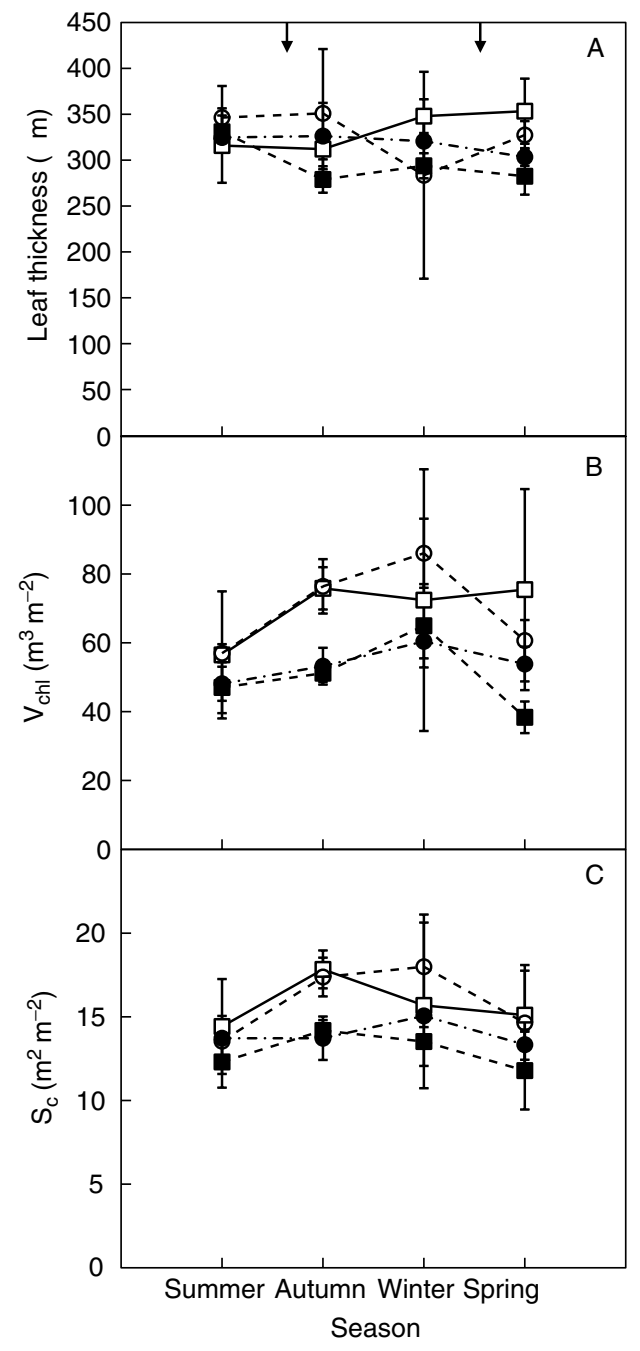

Fig. 4. Seasonal changes in leaf thickness, chloroplast volume $\left(\mathrm{V}_{\mathrm{chl}}\right)$ and chloroplast surface area facing the intercellular space $\left(\mathrm{S}_{\mathrm{c}}\right)$. The average is shown. The values are means $\pm S D(n=3)$. For symbols see Fig. 2 .

involvement of photoinhibition. Photoinhibition by high irradiance in winter has been well documented (e.g. Adams et al. 2004). The third possibility, $\mathrm{CO}_{2}$ diffusion, might have involved in $A$. japonica leaves. Except for winter, $\mathrm{P}_{\max }$ per Rubisco was well correlated with $\mathrm{C}_{\mathrm{i}}$, suggesting that stomatal conductance was responsible. Experimental studies have shown that leaves grown at lower temperatures tend to have lower $\mathrm{C}_{\mathrm{i}}$ (Hikosaka et al. 1999, 2006, Yamori et al. 2006). Additionally we found that the $P_{\max } /$ Rubisco ratio was negatively correlated with chloroplast thickness $\left(\mathrm{V}_{\mathrm{ch}} / \mathrm{S}_{\mathrm{c}}\right.$, Fig. 7). The length of the diffusion path to Rubisco increases with increasing chloroplast thickness (Terashima et al. 2001, 2006), which might have lowered the $\mathrm{CO}_{2}$ concentration at the carboxylation site and thus the $\mathrm{P}_{\max } /$ Rubisco ratio. If the decrease in the $P_{\max } /$ Rubisco ratio was a result

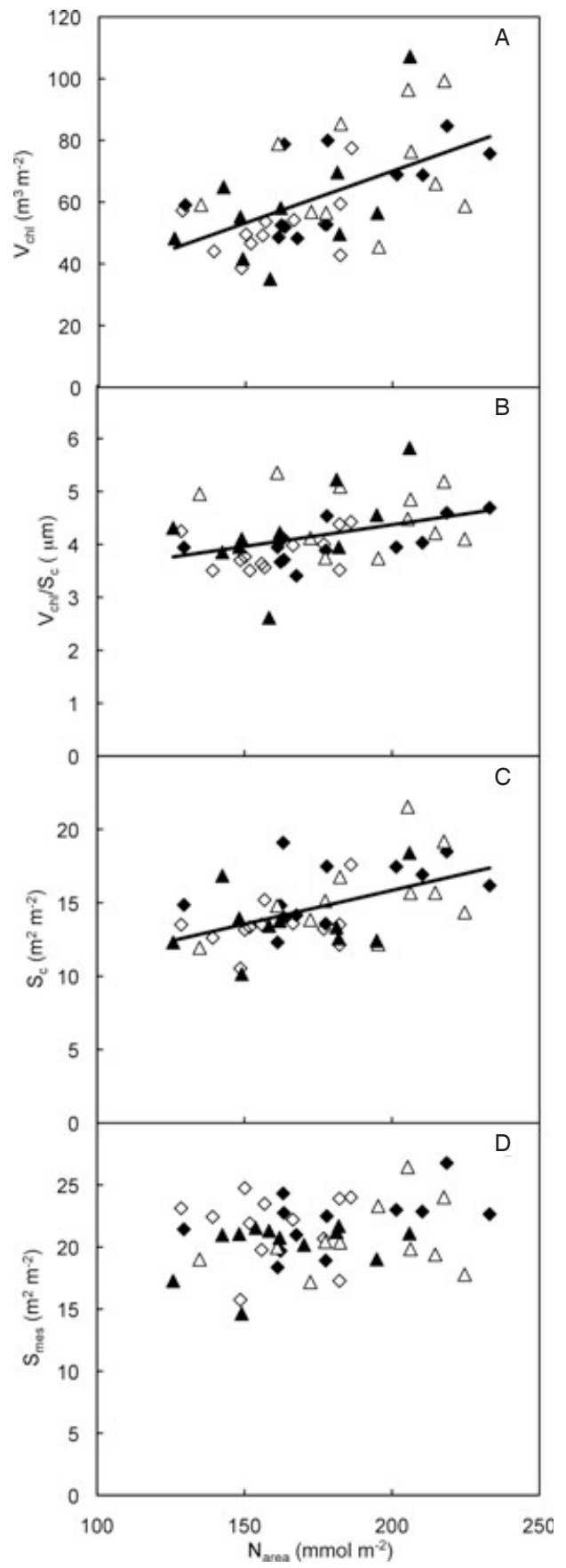

Fig. 5. The relation between $N_{\text {area }}$ and $(A) V_{c h l},(B) V_{c h l} / S_{C}$, (C) $S_{C}$ and (D) $S_{\text {mes }}$ for individual leaves in summer (open diamonds), autumn (closed diamonds) winter (open triangles) and spring (closed triangles). Linear regressions of all data: $(A) y=0.34 x+2.85 P ; 0.001 r^{2}=0.31$; (B) $y=0.008 x+2.73, P<0.05, r^{2}=0.14$; (C) $y=0.05 x+6.65$, $P<0.001, r^{2}=0.27 ;$ (D) NS.

of photoinhibitory damage and/or of an acclimatory response of stomata to prevent water loss, the complementary increase in $\mathrm{V}_{\mathrm{chl}}$ and $\mathrm{S}_{\mathrm{c}}$ rather suggests 

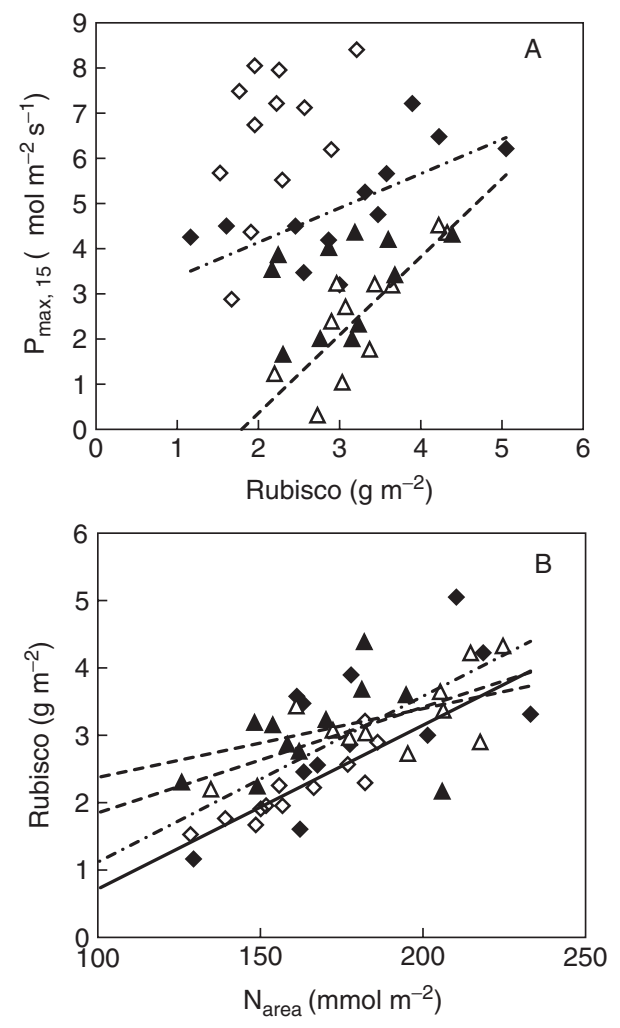

Fig. 6. The relationship between $P_{\max }$ and Rubisco $(A)$ and between Rubisco and $\mathrm{N}_{\text {area }}$ (B) for individual leaves. Significant linear regression for $P_{\max }$ and Rubisco (A): autumn (chain), $y=0.76+2.62, P<0.05$, $r^{2}=0.45$ and winter (dotted line), $y=1.7 x+3.2, P<0.01, r^{2}=0.65$. Linear regression lines for Rubisco and $N_{\text {area }}(B)$ : summer (solid line), $y$ $=0.024 \mathrm{x}-1.7, P<0.001, \mathrm{r}^{2}=0.79$; autumn (chain), $\mathrm{y}=0.025 \mathrm{x}-1.34$, $P<0.05, r^{2}=0.45$; winter (dotted line) $, y=0.016 \mathrm{x}+0.28, P<0.05$, $r^{2}=0.47$; spring (broken line), $y=0.01 x+1.34$, NS. For symbols see Fig. 5.

an increase in the total photosynthetic machinery to function at low temperature, although actual $P_{\max }$ was low. Warren and Adams (2004) also suggested the possibility that the larger amounts of Rubisco are effective for photosynthesis in suboptimal conditions.

It should be noted, however, that all the mesophyll surface was not filled by chloroplasts in winter (Fig. 3, Table 3). It may be because leaves are constructed to acclimate to further increase in irradiance or to further decrease in temperature. Substantial vacant space may also be necessary for other functions such as chloroplast movement (Kasahara et al. 2002, Tholen et al. 2008).

\section{How do environmental conditions affect leaf traits?}

$N_{\text {area }}$ of $A$. japonica leaves increased in autumn to winter (Fig. 2), as has been shown for A. japonica grown under natural conditions (Yamamura and Kimura
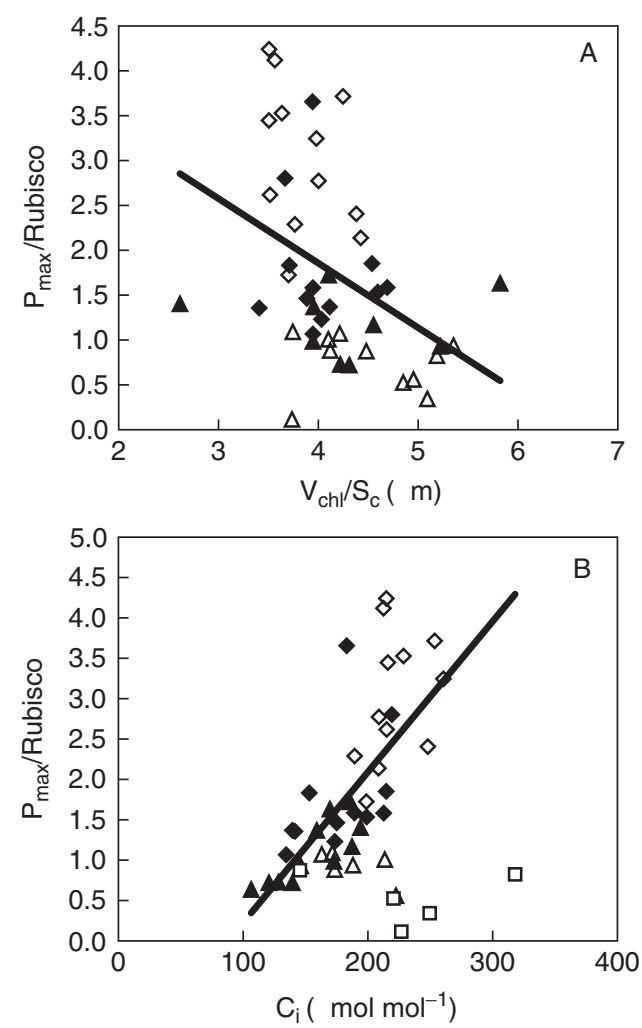

Fig. 7. The relationship between $P_{\max }$ per unit Rubisco $\left(P_{\max } /\right.$ Rubisco, $)$ and chloroplast thickness $\left(\mathrm{V}_{\mathrm{ch} /} / \mathrm{S}_{\mathrm{c}}\right)(\mathrm{A})$, and intercellular $\mathrm{CO}_{2}$ concentration $\left(C_{i}\right)(B)$ for individual leaves. Regression lines: $(A) y=-0.72 x+4.70$, $P<0.01, r^{2}=0.20$ and (B) $y=0.019 x-1.64, P<0.001, r^{2}=0.43$, excluding high irradiance in winter (open squares). For symbols see Fig. 5.

1992, Muller et al. 2005). This has also been shown in perennial evergreen herbs (Skillman et al. 1996), broadleaved evergreens (Miyazawa and Kikuzawa 2005) and in evergreen conifers (Warren and Adams 2001, Han et al. 2004). Under natural conditions, the irradiance in the understory increases strongly with shedding of canopy leaves when air temperature decreases in autumn. Experimental studies have shown that both temperature and irradiance potentially affect $\mathrm{N}_{\text {area }} ; \mathrm{N}_{\text {area }}$ tends to be higher when grown at higher irradiance (e.g. Field 1983, Evans 1989) or at low temperature (Weih and Karlsson 2001, Yamori et al. 2005, Hikosaka 2005). In the natural environment, $N_{\text {area }}$ in $A$. japonica correlated with both irradiance and temperature (Muller et al. 2005). In the present study, where plants were exposed to natural changes in temperature with the controlled irradiances, $\mathrm{N}_{\text {area }}$ was affected by seasonal changes in temperature rather than by growth irradiance (Table 1). This suggests that temperature rather than irradiance primarily determines the changes in $\mathrm{N}_{\text {area }}$ in natural conditions for this species. 
$S_{\text {mes }}$ significantly differed depending on winter irradiance (Tables 1, 3). As new leaves of $A$. japonica that are in bud in winter emerge with the flush of canopy trees, winter irradiance may be detected by the winter bud or by older mature leaves. In F. crenata, Fagus japonica (Uemura et al. 2000) and Chenopodium album (Yano and Terashima 2001), the number of palisade cell layers was determined by the irradiance of mature leaves and not of developing new leaves. Similar mechanisms may be involved in the evergreen species $A$. japonica.

\section{Conclusions}

The present study showed that leaf anatomy is constructed to allow an increase in leaf nitrogen and Rubisco in winter; i.e. mesophyll surface area determined by winter irradiance is large enough to accommodate increased chloroplast volume in winter. If we see leaves only in summer, they look too thick in terms of biomass investment. Although the increase in leaf nitrogen and Rubisco content did not directly increase photosynthetic capacity in winter, it may compensate the decrease in PNUE because of stressful environment in winter.

Acknowledgements - We thank Betty Verduyn for leaf anatomical analysis and Kenichi Sato for his assistance in growing the plants. The technical advice of Ankie Ammerlaan, Henri Groeneveld, Tomoyuki Kawasaki and Frits Kindt is also acknowledged. The members of the Plant Ecology Lab of Tohoku University are thanked for their various supports. This study was supported by the Japan Society for the Promotion of Science with a fellowship and research grant, a MEXT scholarship, KAKENHI (No. 2677001, 19370008), the Global COE Program j03 (Ecosystem management adapting to global change) of the MEXT, Japan and the Dutch Schure-BeijrinckPopping-fund, VSB-fund and Funke-fund.

\section{References}

Adams WW III, Zarter R, Ebbert V, Demmig-Adams B (2004) Photoprotective strategies of overwintering evergreens. Bioscience 54: 41-49

Berry J, Björkman O (1981) Photosynthetic response and adaptation to temperature in higher plants. Annu Rev Physiol 31: 491-543

Björkman O (1981) Responses to different quantum flux densities. In: Lange OL, Nobel PS, Osmond CB, Ziegler $\mathrm{H}$ (eds) Encyclopedia of Plant Physiology, New Series, Vol. xii A. Springer-Verlag, Berlin, 57-109

von Caemmerer S, Evans JR (1991) Determination of the average partial pressure of carbon dioxide in chloroplasts from leaves of several C-3 plants. Aust J Plant Physiol 18: 287-306
Evans JR (1989) Photosynthesis and nitrogen relationships in leaves of C3 plants. Oecologia 78: 9-19

Evans JR, von Caemmerer S, Setchell BA, Hudson GS (1994) The relationship between $\mathrm{CO}_{2}$ transfer conductance and leaf anatomy in transgenic tobacco with a reduced content of rubisco. Aust J Plant Physiol 21: 475-495

Field C (1983) Allocating leaf nitrogen for the maximisation of carbon gain: leaf age as a control on the allocation program. Oecologia 56: 341-347

Han Q, Kawasaki T, Nakano T, Chiba Y (2004) Spatial and seasonal variability of temperature responses of biochemical photosynthesis parameters and leaf nitrogen content within a Pinus densiflora crown. Tree Physiol 24: 737-744

Hikosaka K (2004) Interspecific difference in the photosynthesis-nitrogen relationship: patterns, physiological causes, and ecological importance. J Plant Res 117: 481-494

Hikosaka K (2005) Nitrogen partitioning in the photosynthetic apparatus of Plantago asiatica leaves grown under different temperature and light conditions: similarities and differences between temperature and light acclimation. Plant Cell Physiol 46: 1283-1290

Hikosaka K, Hanba YT, Hirose T, Terashima I (1998) Photosynthetic nitrogen-use efficiency in leaves of woody and herbaceous species. Funct Ecol 12: 896-905

Hikosaka K, Murakami A, Hirose T (1999) Balancing carboxylation and regeneration of ribulose-1, 5-bisphosphate in leaf photosynthesis: Temperature acclimation of an evergreen tree, Quercus myrsinaefolia. Plant Cell Environ 22: 841-849

Hikosaka K, Kato MC, Hirose T (2004) Photosynthetic rates and partitioning of absorbed light energy in photoinhibited leaves. Physiol Plant 121: 699-708

Hikosaka K, Ishikawa K, Borjigidai A, Muller O, Onoda Y (2006) Temperature acclimation of photosynthesis: mechanisms involved in the changes in temperature dependence of photosynthetic rate. J Exp Bot 57: 291-302

Hirotsu N, Makino A, Yokota S, Mae T (2005) The photosynthetic properties of rice leaves treated with low temperature and high irradiance. Plant Cell Physiol 46: 1377-1383

Huner NPA, Öquist G, Sarhan F (1998) Energy balance and acclimation to light and cold. Trends Plant Sci 3: 224-230

Kasahara M, Kagawa T, Oikawa K, Suetsugu N, Miyao M, Wada M (2002) Chloroplast avoidance movement reduces photodamage in plants. Nature 420: 829-832

Katahata S, Naramoto M, Kakubari Y, Mukai Y (2005) Photosynthetic acclimation to dynamic changes in environmental conditions associated with deciduous 
overstory phenology in it Daphniphyllum humile, an evergreen understory shrub. Tree Physiol 25: 437-445

Miyazawa Y, Kikuzawa K (2005) Winter photosynthesis by saplings of evergreen broad-leaved trees in a deciduous temperate forest. New Phytol 165: 857-866

Miyazawa SI, Livingston NJ, Turpin DH (2006) Stomatal development in new leaves is related to the stomatal conductance of mature leaves in poplar. Populus trichocarpa x P. deltoides. J Exp Bot 57: 373-380

Miyazawa Y, Kikuzawa K, Otsuki K (2007) Decrease in the capacity for RuBP carboxylation and regeneration with the progression of cold-induced photoinhibition during winter in evergreen broadleaf tree species in a temperate forest. Funct Plant Biol 34: 393-401

Mott KA, Woodrow IE (2000) Modelling the role of Rubisco activase in limiting non-steady-state photosynthesis. J Exp Bot 51: 399-406

Muller O, Hikosaka K, Hirose T (2005) Seasonal changes in light and temperature affect the balance between light harvesting and light utilisation components of photosynthesis in an evergreen understory shrub. Oecologia 143: 501-508

Oguchi R, Hikosaka K, Hirose T (2003) Does the photosynthetic light-acclimation need change in leaf anatomy? Plant Cell Environ 26: 505-512

Oguchi R, Hikosaka K, Hirose T (2005) Leaf anatomy as a constraint for photosynthetic acclimation: differential responses in leaf anatomy to increasing growth irradiance among three deciduous trees. Plant Cell Environ 28: 916-927

Oguchi R, Hikosaka K, Hiura T, Hirose T (2006) Leaf anatomy and light acclimation in woody seedlings after gap formation in a cool-temperate deciduous forest. Oecologia 149: 571-582

Oguchi R, Hikosaka K, Hiura T, Hirose T (2008) Cost and benefits of photosynthetic light acclimation by tree seedlings in response to gap formation. Oecologia 155: 665-675

Park IK, Tsunoda S (1979) Effect of low-temperature on chloroplast structure in cultivars of rice. Plant Cell Physiol 20: 1449-1453

Röhrig E (1991) Climatic conditions. In: Röhrig E, Ulrich B (eds) Temperate Deciduous Forests. Elsevier, pp 7-16

Rothstein DE, Zak DR (2001) Photosynthetic adaptation and acclimation to exploit seasonal periods of direct irradiance in three temperate, deciduous-forest herbs. Funct Ecol 15: 722-731

Sims DA, Pearcy RW (1992) Response of leaf anatomy and photosynthetic capacity in Alocasia macrorrhiza (Araceae) to a transfer from low to high light. Am J Bot 79: 449-455

Skillman JB, Strain BR, Osmond CB (1996) Contrasting patterns of photosynthetic acclimation and photoinhibition in two evergreen herbs from a winter deciduous forest. Oecologia 107: 446-455

Terashima I, Miyazawa S-I, Hanba YT (2001) Why are sun leaves thicker than shade leaves? Consideration based upon analysis of $\mathrm{CO}_{2}$ diffusion in the leaf. J Plant Res 114: 93-105

Terashima I, Hanba YT, Tazoe Y, Vyas P, Yano S (2006) Irradiance and phenotype: comparative ecodevelopment of sun and shade leaves in relation to photosynthetic $\mathrm{CO}_{2}$ diffusion. J Exp Bot 57: 343-354

Thain JF (1983) Curvature correction factors in the measurement of cell surface areas in plant tissues. J Exp Bot 34: 87-94

Tholen D, Boom C, Noguchi K, Ueda S, Katase T, Terashima I (2008) The chloroplast avoidance response decreases internal conductance to $\mathrm{CO}_{2}$ diffusion in Arabidopsis thaliana leaves. Plant Cell Environ 31: 1688- 1700

Uemura A, Ishida A, Nakano T, Terashima I, Tanabe H, Matsumoto $Y$ (2000) Acclimation of leaf characteristics of Fagus species to previous-year and current-year solar irradiances. Tree Physiol 20: 945-951

Warren CR, Adams MA (2001) Distribution of N, Rubisco and photosynthesis in Pinus pinaster and acclimation to light. Plant Cell Environ 24: 597-609

Warren CR, Adams MA (2004) Evergreen trees do not maximize instantaneous photosynthesis. Trends Plant Sci 9: 270-274

Weih M, Karlsson PS (2001) Growth response of Mountain birch to air and soil temperature: is increasing leaf-nitrogen content an acclimation to lower air temperature? New Phytol 150: 147-155

Yamamura Y, Kimura M (1992) Matter-economical roles of evergreen foliage of Aucuba japonica, an understory shrub in the warm-temperate region of Japan 2. dynamics and budgets of nutrients. Bot Mag (Tokyo) 105: 95-104

Yamori W, Noguchi K, Terashima I (2005) Temperature acclimation of photosynthesis in spinach leaves: analyses of photosynthetic components and temperature dependencies of photosynthetic partial reactions. Plant Cell Environ 28: 536-547

Yamori W, Noguchi K, Hanba YT, Terashima I (2006) Effects of internal conductance on the temperature dependence of the photosynthetic rate in spinach leaves from contrasting growth temperatures. Plant Cell Physiol 47: 1069-1080

Yano S, Terashima I (2001) Separate localization of light signal perception for sun or shade type chloroplast and palisade tissue differentiation in Chenopodium album. Plant Cell Physiol 42: 1303-1310

Edited by W. S. Chow 